\title{
Diet and haemostatic processes
}

\author{
Hester H. Vorster ${ }^{1}$, John H. Cummings ${ }^{2}$ and Johann C. Jerling ${ }^{1}$ \\ ${ }^{1}$ Department of Nutrition, Potchefstroom University for Christian Higher Education, \\ Potchefstroom, 2520 South Africa: ${ }^{2}$ MRC Dunn Clinical Nutrition Centre, \\ Cambridge, $C B 22 D H, U K$.
}

\begin{abstract}
Diet plays an important role in the primary and secondary prevention of cardiovascular disease. The growing perception that abnormal haemostatic processes of coagulation, platelet aggregation and fibrinolysis contribute to cardiovascular disease aetiology motivated this review on the relationships of diet, specific foods and nutrients with haemostatic function. Functional endpoints that reflect the function and status of some of these processes and which can be measured in dietary trials are identified. The effects of energy intake and expenditure, alcohol, total fat and specific fatty acids, non-starch polysaccharides (dietary fibre), antioxidant nutrients and some foods on a variety of haemostatic markers are reviewed. The results indicate that the prudent low-fat, high-fibre diet and maintenance of ideal body weight recommended to protect against and treat hyperlipidaemia and coronary heart disease will also benefit haemostatic profiles. It is concluded that more research on specific effects is needed for improved recommendations on a population level for prevention of cardiovascular disease.
\end{abstract}

\section{Introduction}

The term haemostasis means prevention of blood loss (Guyton, 1991). In this review the term is used collectively to describe the processes of coagulation, platelet aggregation, fibrinolysis and secretion of substances by vascular endothelium which influence these functions. Abnormal haemostasis, characterized by an imbalance in procoagulant and anticoagulant activities, is now accepted as a major risk factor for atherosclerosis, thrombosis and resultant cardiovascular disease (reviewed by Tanaka \& Sueishi, 1993; Vorster \& Venter, 1994). It is also accepted that diet, inter alia through its effects on lipid metabolism and antioxidant properties, plays an important role in the primary and secondary prevention of cardiovascular disease (Ulbricht \& Southgate, 1991). In this review the relationship between diet and haemostasis is explored to test the hypothesis that the protective effects of diet are also mediated through the haemostatic system. A better understanding of this relationship could lead to improved dietary guidelines for prevention and treatment of cardiovascular disease.

The notion that diet influences haemostasis is not new. However, despite many reports and reviews (Marckmann, 1995; Vorster et al. 1997) the relationships of the total diet, as well as specific foods and nutrients, with the different variables of haemostasis are far from clear. One 
reason is that scientists are only now beginning to understand the complexities of the different components of the haemostatic system, with its highly specific and intricate mechanisms of regulation and control. Furthermore, it has been suspected for over a century that thrombotic elements in blood must influence atherosclerosis, but only during the past decade have the powerful relationships of components of the haemostatic system with atherosclerosis and thrombosis and with other risk factors of cardiovascular disease been firmly established. Other reasons are the limitation of dietary epidemiology, the difficulties with dietary placebos, dietary control and compliance in clinical trials with free-living subjects, as well as our inability to draw valid conclusions from results of studies with different and sometimes inappropriate designs.

In the following sections, the components of the haemostatic system will be briefly outlined, and functional endpoints that could be measured in dietary trials identified. The known effects of diet, specific nutrients and foods will then be summarized, possible mechanisms of actions delineated, and directions for future research and practical applications suggested.

\section{Haemostasis}

\section{Components and interrelationships}

The haemostatic system protects the integrity of the vascular system by preventing haemorrhage and promoting tissue defence and repair after injury. Haemostasis is the culmination of a series of precisely controlled and interrelated actions involving the clotting factors, fibrinolytic enzymes, platelets and the vascular endothelium (Takada et al. 1994).

The balance between procoagulant and anticoagulant activities in the system is carefully controlled by the specificity and interaction of molecules from the different components of the system, regulated by positive and negative feedback mechanisms. This balance ensures sufficient blood flow to all tissues and organs under normal circumstances. The interaction of the molecules from the different components of the system also ensures that when the system is triggered by injury, the coagulant activities and subsequent fibrinolysis are localized within the area of injury. Disturbance of haemostatic balance may lead either to thrombosis (clot formation inside a blood vessel) and atherosclerosis, or a bleeding tendency.

Some of the interrelationships of the different components of the haemostatic system are illustrated in Fig. 1. The figure shows how thrombin, generated in the coagulation component of the system, also influences events in the fibrinolytic, platelet and endothelial cell components (Bertina et al. 1992; Esmon, 1993).

Understanding of these interrelationships, and the compensatory control mechanisms in all parts of the system to maintain haemostatic balance, is important for understanding and evaluating the effects of diet on the system.

\section{Coagulation}

Blood coagulation is an autocatalytic, self-limiting process which is triggered by tissue injury. It requires the sequential 'cascade' activation of a series of proteinase zymogens of which some combine with a protein cofactor on membrane surfaces for further activation, culminating in the formation of thrombin from prothrombin, with release of prothrombin fragments $1+2$. Thrombin formation must be in sufficient quantities to overcome the effect of antithrombins 

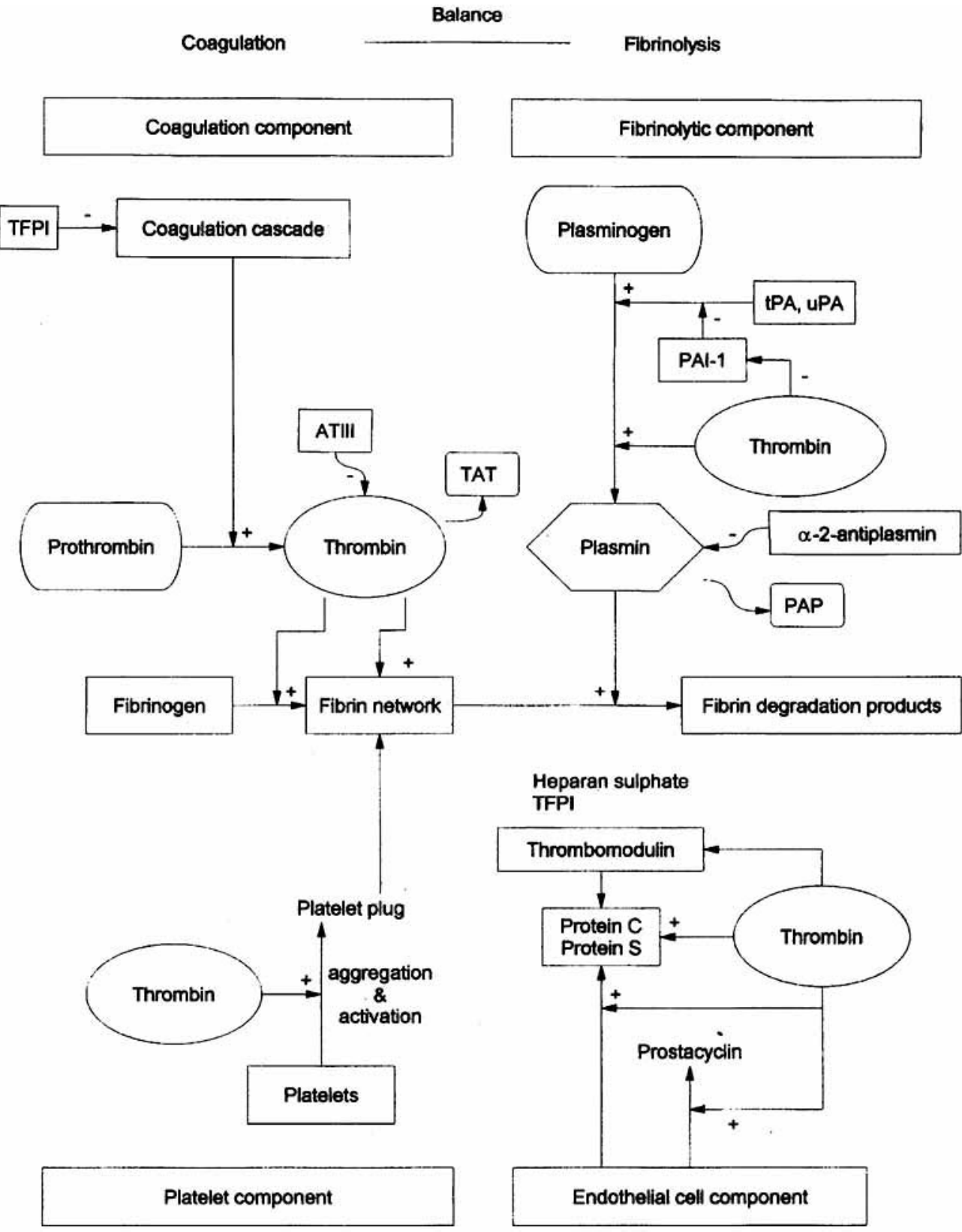

Fig 1. Interrelationships between the coagulation, fibrinolytic, platelet and endothelial cell components of the haemostatic system. Thrombin generated in the coagulation component influences events in other components. AT III, antithrombin III; PAI-1, plasminogen activator inhibitor 1; PAP, plasmin-antiplasmin complex (marker of plasmin generation); TAT, thrombin-antithrombin complex (marker of thrombin generation); TFPI, tissue factor pathway inhibitor; tPA, tissue type plasminogen activator; UPA, urokinase type plasminogen activator. 
and proteinase inhibitors (antithrombin III, protein $\mathrm{C}$, protein $\mathrm{S}$, thrombomodulin and tissue factor pathway inhibitor). Thrombin cleaves four peptide bonds in fibrinogen, forming soluble monomers and the two negatively charged fibrinogen peptides $\mathrm{A}$ and $\mathrm{B}$. The monomers polymerize linearly and laterally to form an insoluble fibrin network or white clot (reviewed by Verstraete, 1991). The coagulation mechanism is normally active at a low level, even without tissue injury. Small elevations in coagulation factor activities and concentrations give rise to a hypercoagulable (Miller, 1992) and therefore also probably to a prethrombotic (Rosenberg \& Bauer, 1992) state, associated with increased atherosclerosis and thrombosis. Raised fibrinogen concentration and factor VII coagulant activity $\left(\mathrm{VII}_{\mathrm{c}}\right)$ are the two clotting factors that have been identified in epidemiological and clinical studies as risk factors for cardiovascular disease (reviewed by Vorster \& Venter, 1994; Mennen et al. 1996) and which may be influenced by diet (Vorster et al. 1997).

\section{Fibrinolysis}

The fibrinolytic system, through the proteolytic action of a blood component, plasmin, degrades the fibrin network by digesting fibrin and clotting factors associated with the clot. Two types of plasminogen activators, tissue type (t-PA) and urokinase type (u-PA) are responsible for the conversion of inactive plasminogen to active plasmin. The fibrinolytic process is further regulated and influenced by the concentrations and activities of $\alpha$-2-antiplasmin, plasminogen activator inhibitors (PAI-1 and PAI-2) as well as thrombin and fibrin itself (reviewed by Van der Bom et al. 1996).

The fibrinolytic system is not only responsible for the dissolution of blood clots. It is involved in cell migration and wound healing. Its role in tumour invasion and metastasis, atherosclerosis, thrombosis, embolism and bleeding makes the modulation of fibrinolytic function likely to become an important approach in the prevention of many diseases (Hamsten \& Eriksson, 1995).

The fibrinolytic capacity of an individual is the ability to react to fibrin formation. Increased concentration and/or activity of PAI- 1 is probably the main cause of impaired fibrinolytic capacity. PAI-1 is the major plasminogen activator inhibitor. High concentrations and activities of PAl-1, possibly because of increased insulin secretion (Vague et al. 1986) or insulin resistance (Juhan-Vague et al. 1993) have been shown repeatedly in epidemiological and clinical studies to be a risk factor for atherosclerosis and thrombosis (Aznar \& Estelles, 1994). PAI-1 is a protein which is highly regulated at a transcriptional level. Because of both up and down regulation of PAI- 1 synthesis and secretion, a large number of cellular functions and circulating molecules could influence PAI-1 concentrations.

\section{Platelet aggregation}

Platelet aggregation and the formation of a platelet plug is part of the haemostatic mechanism to prevent blood loss from injured vessels. Aggregating platelets participate in fibrin network formation, clot retraction and tissue repair. Damaged endothelium exposes collagen. Platelets adhere to the collagen, form platelet aggregates and release their granule contents, which activate further platelet aggregation and the coagulation cascade. In addition to exposure to collagen, many other factors such as thrombin, thromboxane A, fibrinogen (Mikhailidis et al. 1985) and also oxidized low density lipoprotein cholesterol (Weidtmann et al. 1995) may 
activate platelets. Increased platelet aggregation plays an important role in the development of atherosclerosis and thrombosis (Packham \& Mustard, 1986).

\section{Endothelial cell participation}

Endothelial cells line blood vessels and passively separate the circulating blood from tissues. One of their major functions is to maintain a nonadhesive antithrombotic luminal surface which contributes to the fluidity of blood. They have also the ability to respond to their physical, chemical and humoral environment by producing numerous substances which influence vascular smooth muscle tone, haemostasis, cellular proliferation and inflammatory and immune responses (Rubanyi, 1993).

The antithrombotic properties of the endothelium are maintained by the synthesis and secretion of anticoagulant and profibrinolytic substances such as prostacyclin, proteins $\mathbf{C}$ and $\mathbf{S}$, thrombomodulin, tissue factor pathway inhibitor, glycosaminoglycans (including heparan sulphate) and plasminogen activators tPA and uPA (Dittman \& Majerus, 1990).

When endothelial cells are injured or stimulated by substances such as thrombin, or inflammatory and pathological agents, their anticoagulant products are downregulated, and they acquire procoagulant properties by secreting inter alia coagulation factors, PAI-1, and tissue factor (Tanaka \& Sueishi, 1993), which contribute to the development of atherosclerosis and thrombosis.

\section{Functional endpoints to measure}

To diagnose hypercoagulable and prethrombotic states and to monitor effects of dietary or other interventions, it is important that sensitive endpoints or markers that reflect disturbances in the haemostatic balance and which correlate with atherosclerosis and thrombosis should be identified and measured. Unfortunately, few really sensitive markers are available.

In the past, clinical tests have been developed and standardized to monitor bleeding tendencies rather than hypercoagulability. However, recent advances in our understanding of the regulation of haemostatic balance have led to the development of assays which can evaluate aspects of the in vivo function and status of the system.

Haemostatic balance can be shifted towards a procoagulant, profibrinolytic, anticoagulant or antifibrinolytic direction, depending on where changes in the system occur. For example, the balance will be shifted towards a procoagulant state during hypercoagulability of plasma and/or impaired fibrinolysis, hyperaggregability of platelets, loss of the anticoagulant properties of vascular endothelial cells, as well as increased blood viscosity and reduced flow with vortices (Rosenberg \& Bauer, 1992). Miller (1993) points out that the time is approaching when the hypercoagulant state of plasma, like the hyperlipidaemic states, will be quantified and separated into different types. However, for a proper diagnosis and classification, much more information is needed on the normal ranges of the different markers, their distribution in different age and gender groups, and the compensatory adjustments and adaptations in the different components of the system in an attempt to maintain haemostatic balance.

Other complicating factors are the short plasma half-life of some markers, differences in fasting and postprandial plasma samples, effects of blood sampling methods e.g. stasis which activates endothelium to secrete antithrombolic products $v$. nonstasis, circadian fluctuations of many of the variables, relationships of in vitro measurements with in vivo events, as well as the 
assay method. For example, fibrinogen concentration measured by functional methods based on coagulation time will differ from those measured by immunological, precipitation or gravimetric methods (Palareti et al. 1992). Also, more information could be obtained by measuring the different molecular weight variants of fibrinogen (Nieuwenhuizen, 1994).

Table 1 summarizes some of the more sensitive markers of the functions of the coagulation, fibrinolytic, platelet and endothelial cell components of the haemostatic system, and the information they provide. In addition to measurement of the concentration and activity of many coagulation and fibrinolytic factors and enzymes, measurement of factor and enzyme fragments and complexes will give information on in vivo coagulation and fibrinolytic processes and turnover. Measurement of fibrin network characteristics is not widely done but can give indications of thrombogenicity, atherogenicity and the potential of the network to be digested by plasmin (Veldman, 1996). Measurements of the concentration and activity of the inhibitors of coagulation will give information on the ability of vascular endothelial cells to respond to stimuli affecting coagulation.

\section{Diet and haemostasis}

\section{Effects of energy intake and expenditure}

The relationships of energy intake and expenditure with some haemostatic variables have been examined in baseline epidemiological surveys, during energy restricted (weight loss) dietary interventions, during increases in energy expenditure (activity, exercise) and combinations of diet and exercise.

\section{Energy intake and obesity}

There is agreement that obesity is associated with a prethrombotic and hypercoagulable state characterized by increased plasma fibrinogen (Vorster et al. 1989), increased PAI-1 (Iso et al. 1993b), decreased tPA secretion after venous occlusion (Licata et al. 1995), impaired fibrinolytic capacity (Cepelak et al. 1991), and increased plasma viscosity (Fanari et al. 1993). Subjects with abdominal (android) obesity may have a more adverse haemostatic profile than those with peripheral (gynoid) obesity. Krobot et al. (1992) found a positive correlation between waist-hip ratio and fibrinogen in the second MONICA trial. The same correlation was observed by Avellone et al. (1994) in premenopausal women. These authors also found higher factor VII and PAI-1 activities and lower IPA antigen levels after the venous occlusion test in women with abdominal obesity. However, Oosthuizen et al. (1996) could not demonstrate significant differences in fibrinogen concentrations in the blood of android and gynoid obese African women and concluded that in these women the putative 'healthy' obesity state was associated with normal lipoprotein profiles but increased plasma fibrinogen.

\section{Energy restricted diets}

Energy restricted diets which result in weight loss improve haemostatic profiles. Decreases have been reported in blood viscosity (Poggi et al. 1994), factor $\mathrm{VII}_{\mathrm{c}}$ (Slabber et al. 1992), PAI1 concentration and activity (Huisveld et al. 1990; Peternel et al. 1994) and in the tPA/PAI-1 complex (Calles-Escandon et al. 1996). Improvement in fibrinolytic activity during weight loss has been reported (Peternel et al. 1994) while Calles-Escandon et al. (1996) also showed increases in the plasmin-antiplasmin complex. In some studies (Folsom et al. 1993; CallesEscandon et al. 1996) the decreases in PAI-1 and improvement in fibrinolytic capacity 
correlated with decreases in serum triacylglycerols. However, Peternel et al. (1994) reported that improvements in fibrinolytic activity were not accompanied by changes in blood lipids.

The effect of low energy diets and weight loss on plasma fibrinogen is more controversial. Fanari et al. (1993) reported a reduction while Gelmini et al. (1989) also found that a low energy, salt restricted diet decreased fibrinogen in elderly obese women with hypertension. However, Palareti et al. (1994) could demonstrate no effect of weight loss on fibrinogen, while Slabber et al. (1992) even found an increase in obese subjects following a very low energy diet. These conflicting results may be explained by effects of weight loss on increasing circulating free fatty acids, which is known to stimulate hepatic fibrinogen production (Pilgeram \& Pickart, 1968). Vorster et al. (1989) showed that during an 8 week period of diet induced weight loss, fibrinogen levels fluctuated in a similar manner to free fatty acids. During periods of rapid loss, fibrinogen and free fatty acids rose and both decreased during periods of slower weight loss.

\section{Energy expenditure: exercise}

Exercise (physical activity or training) protects against coronary heart disease (CHD) (Morris, 1994). It is hypothesized that part of this protection is mediated through effects on haemostasis (Connelly et al. 1992). From the available literature it is difficult to gather which haemostatic effects of exercise are caused by increased energy expenditure, usually coupled with increased intake, which by improved energy balance, and which by exercise and physical fitness per se. Studies with different intensity and duration of exercise and uncertainties in defining optimal exercise further complicate comparison and interpretation of results.

Nevertheless, there is agreement that fibrinolytic capacity is increased by exercise (Boman et al. 1994) especially because of effects on PAI- 1 and tPA. One study on patients who had myocardial infarction (Suzuki et al. 1992) found that exercise decreased plasminogen, tPA antigen, $\boldsymbol{x}$-2-antiplasmin, PAI- 1 and the plasmin-antiplasmin complex, indicating decreased fibrinolysis. However, the same study found decreases in fibrinogen, factor VIII coagulant activity, thrombin-antithrombin complex, and activities of antithrombin III and plasminogen, indicating a decrease in hypercoagulability. The authors concluded that the decreased fibrinolysis was a result of the decrease in coagulability.

Effects on plasma fibrinogen are less clear. Rankinen et al. (1994) reported lower fibrinogen concentrations in active than in inactive men, while Connelly et al. (1992) showed in a large group of 3967 men 45-69 years old that strenuous exercise was associated with lower fibrinogen than mild exercise. Factors X and VII were also lowered by exercise in these two studies respectively. However, El-Sayed \& Davies (1995) could not demonstrate a lowering of fibrinogen with increased exercise. But their two groups of young healthy subjects had relatively low fibrinogen concentrations of 2.43 and $2.47 \mathrm{~g} /$. Vanninen et al. (1994) reported that the increased fibrinogen found in diabetic subjects could be lowered by exercise accompanied by improved glycaemic control, while Suzuki et al. (1992) also showed that exercise training lowered fibrinogen during the recovery phase of patients who had had myocardial infarction. The inference is that it would be difficult to lower a 'normal' fibrinogen level in healthy subjects.

Acute and long term exercise may have separate effects on haemostasis. Acute bouts of dynamic exercise increased tPA activity and decreased PAI-1 activity, but values returned to pre-exercise values after $24 \mathrm{~h}$ (Rankinen et al. 1995). Wang et al. (1995) showed that acute bouts of strenuous exercise transiently increased platelet adhesiveness and aggregability, but that long term endurance training suppressed it.

Little is known about the combined effect of dietary energy restriction and increased expenditure (exercise). Svendsen et al. (1996) found that exercise conferred no additional 


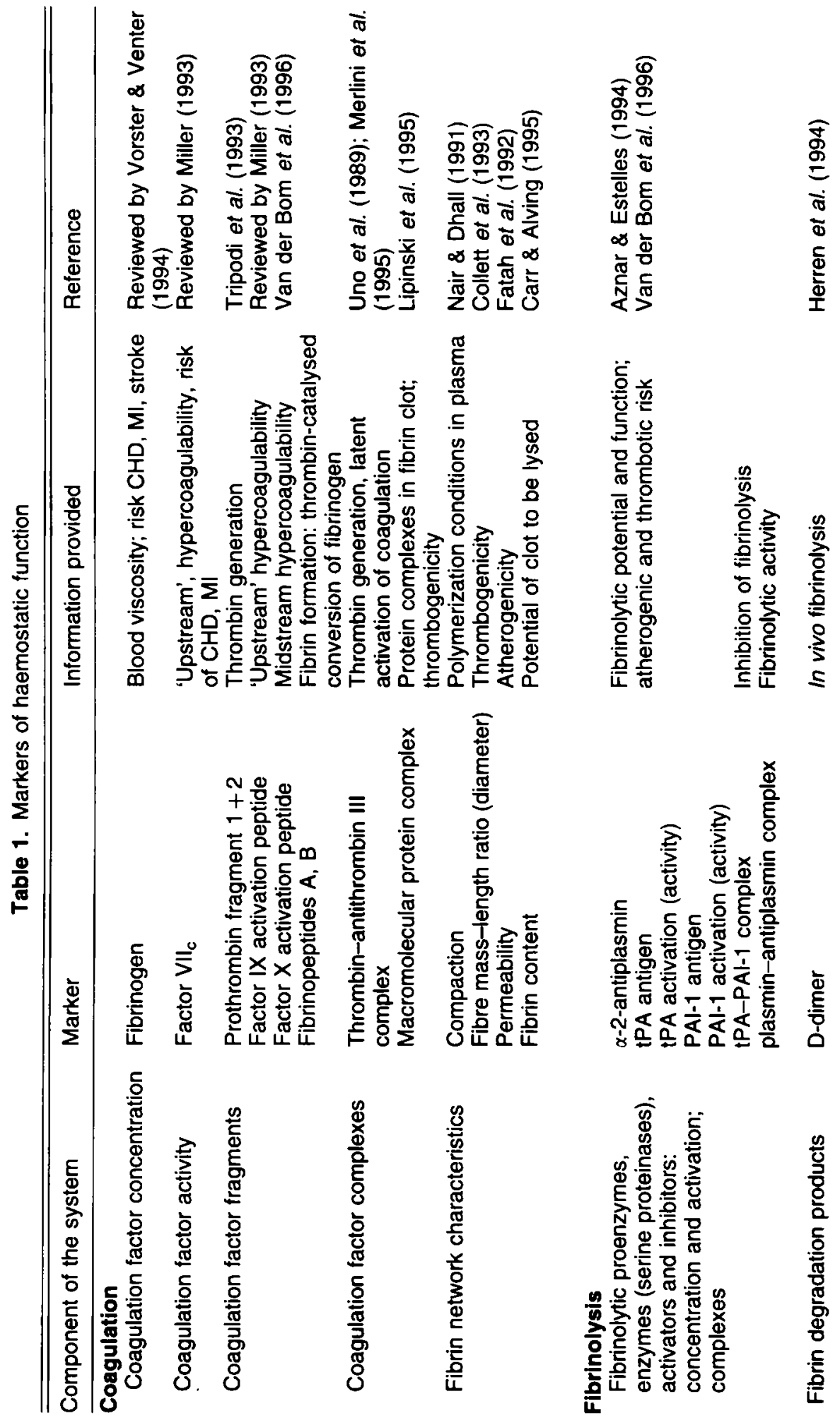




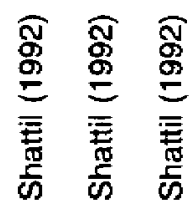

뮴 总

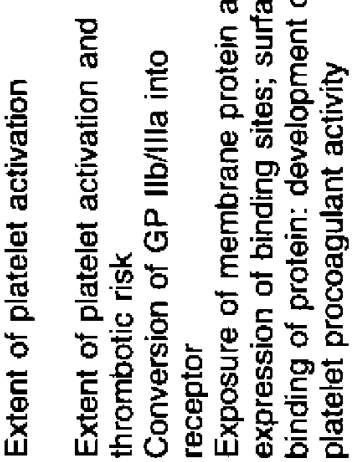

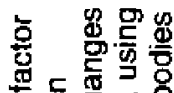

등 흥응

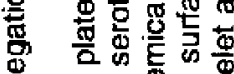

동 离要

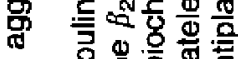

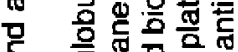

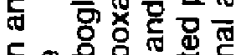

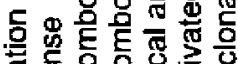

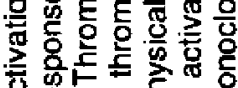

造这母元

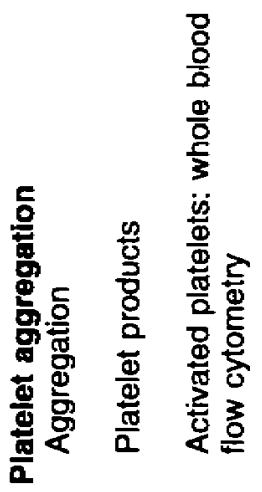

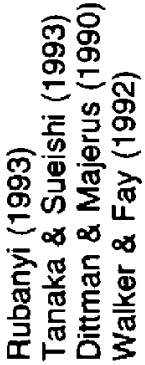

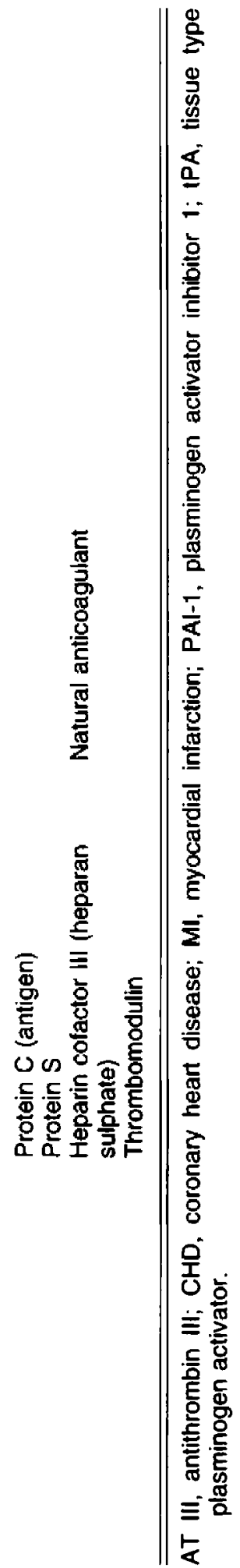


benefit to the improvement in fibrinolytic profiles observed in obese post-menopausal women following energy restricted diets.

Therefore, high energy intake and inactivity leading to obesity are associated with hypercoagulability and decreased fibrinolytic capacity, while decreases in energy intake and increases in physical activity are associated with improvement of many haemostatic variables. The mechanisms through which these effects are mediated are not known. Reduced energy intake, weight loss and increased exercise are known to increase insulin sensitivity, which may be related to some haemostatic variables (Juhan-Vague et al. 1993).

\section{Effects of alcohol intake}

Although alcohol (ethanol) is not strictly regarded as a nutrient, it does provide dietary energy and forms an important part of the diet and social life of many people. Moderate alcohol consumption is known to protect against CHD (Doll et al. 1994). This characteristic has been ascribed to beneficial effects on high density lipoprotein cholesterol levels, but new evidence indicates that effects on haemostasis may also contribute. Renaud \& De Logeril (1992) hypothesize that the 'French paradox for CHD' (low mortality despite high intakes of saturated fat, and HDL cholesterol levels that are similar to those in other populations with high CHD mortality) may be a result of effects of the high wine consumption of the French population on platelet aggregation.

There is consensus from epidemiological surveys that moderate alcohol consumption is associated with lower plasma fibrinogen (Krobot et al. 1992) and with increased fibrinolytic activity (Meade et al. 1979), mainly because of increases in tPA (Lee et al. 1995). Paradoxically, alcohol consumption increases PAI-1 activity (Marques-Vidal, 1995). An increase in PAI-1 activity was also seen one hour after a meal containing alcohol and persisted after an overnight fast (Veenstra et al. 1993). The short term or acute studies also showed decreases in tPA antigen levels and varying effects on platelet aggregation (Veenstra et al. 1993; Hendriks et al. 1994). However, these postprandial effects were mostly temporary and fasting haemostatic profiles on the following morning were consistent with a lower CHD risk.

Part of the long term antithrombotic effects of moderate alcohol consumption can be ascribed to beneficial effects on platelet aggregation. Struck et al. (1994) showed that both red and white wine reduced thrombin initiated platelet aggregation. Renaud et al. (1992) found in the Caerphilly prospective heart disease study that alcohol consumption was associated with an increased sensitivity of platelets to thrombin induced aggregation but a decreased aggregation response to ADP and collagen stimulation. The type of fat intake may modulate response of platelets to aggregation stimuli (Renaud et al. 1992).

There is some speculation on mechanisms through which alcohol consumption may affect haemostasis. Acetaldehyde, one of the products of alcohol metabolism, could react with coagulation proteins to alter their function (Basista et al. 1994) or form adducts with platelets which may interfere with their activation and aggregation (Spertini et al. 1992). Another possibility is that ethanol inhibits secretion of phospholipase $A_{2}$ (EC 3.1.1.4) with resultant suppressed arachidonic acid release from platelet membranes, and decreased prostanoid formation and aggregation responses (Stubbs \& Rubin, 1992). The differences in acute (postprandial) and long term effects suggest that ethanol and its metabolic products may have different and even opposing effects on haemostatic variables. 
The relationships of dietary fat content and type with haemostatic variables have received more attention than those of other nutrients, probably because of the established association of fat intake with CHD, and the early recognition of the powerful effects of the n-3 fatty acids (Eskimo or fish diet) on platelet function.

\section{Total fat intake}

There is agreement from results of epidemiological surveys as well as both acute and long term dietary studies that high total dietary fat intakes, rather than type of fat, are associated with increased factor $\mathrm{VII}_{\mathrm{c}}$ during fasting or postprandial states (Bladbjerg et al. 1994; Mennen et al. 1996). Low fat intake correlates with low factor VII $_{c}$ (Vaisanen et al. 1995). There is some evidence that high fat intake may impair fibrinolytic activity. Rankinen et al. (1994) reported positive correlations with PAI-1 and tPA. Ho et al. (1995) found after a 3-day increase in fat intake that the IPA response to venous occlusion was suppressed, while Kozima et al. (1993) showed that PAI- 1 was increased and clot lysis time prolonged $8 \mathrm{~h}$ after intake of $100 \mathrm{~g}$ butter. Ferlito \& Di Mauro (1990), however, could not show any adverse effect of an oral fat load on tPA, $\beta$-thrombomodulin or D-dimer, a degradation product of cross-linked fibrin. The latter is regarded by many as an indicator of an activated fibrinolytic system and is increased during many pathological states such as deep vein thrombosis.

Little is known about effects of total fat intake on other haemostatic variables. Rankinen et al. (1994) reported a positive correlation with factor X, while Vorster et al. (1987) found higher fibrinogen and factor IX levels in subjects who habitually followed a diet high in fat, cholesterol, and animal protein and low in fibre compared to a control group on a low fat, high fibre diet.

There is some speculation on the mechanisms whereby total fat intake may influence haemostasis, and especially factor VII concentration and activation (reviewed by Mennen et al. 1996). Briefly, it is thought that factor VII may bind with triacylglycerols with a resultant prolonged half-life; that triacylglycerol-rich lipoprotein metabolism may lead to the formation of negatively charged micelles capable of activating factor XII which then activates factor VII; and that the increased activation of the extrinsic pathway will lead to increased prothrombin fragment $1+2$ and thrombin formation, which will stimulate synthesis of all vitamin $\mathrm{K}$ dependent coagulation factors.

Theoretically, fat intake may therefore influence haemostasis indirectly through effects on blood lipoproteins. This is supported by correlations between blood lipids and haemostatic variables. Serum triglycerides are positively associated with factor VII $_{c}$ (Assmann \& Schulte, 1992), bleeding times (Mundal et al. 1994) and with tPA and PAI-1 (Iso et al. 1993a). Apo B levels also correlate with factor $\operatorname{VII}_{\mathrm{c}}$ (Vaisanen et al. 1995) while high density lipoprotein cholesterol has a negative correlation with fibrinogen (Iso et al. 1993b) and Lp (a) a positive one (Howard et al. 1994).

It can therefore be expected that lowering fat intake should improve haemostatic profiles. Miller (1993) reviewed the evidence that treatment of hypertriglyceridaemia leads to lowering of factor $\mathrm{VII}_{\mathrm{c}}$, and concluded that some lipid lowering drugs protect against $\mathrm{CHD}$ by reducing coagulability of blood. There is also some evidence that lower fat intakes decrease PAI- 1 (Sundell et al. 1991). The absence of effects reported by Marckmann et al. (1992) and Velthuiste Wierik et al. (1996) who had relatively modest fat intake reductions in their study designs, and also the studies of Vorster et al. (1987) and Marckmann et al. (1993) suggest that only 
substantial reductions in fat intake, or concomitant changes in type of fat and other nutrient intakes, will have significant beneficial effects on haemostasis.

In addition to increased levels of factor $\mathrm{VII}_{c}$ being an accepted risk factor for $\mathrm{CHD}$, the relationship between fat intake, hyperlipidaemia and haemostasis may also be important at an acute, clinical level. Altomare et al. (1993) have shown that the infusion of a lipid emulsion, used as a standard component of parenteral nutrition, significantly reduced tPA and had no effect on PAI-1 release after 10 min venous occlusion. This haemostatic profile is associated with an increased risk of thrombosis.

\section{Type of fatty acid}

There is an increasing perception and growing evidence that the relationships between CHD and intakes of fatty acids with different chain lengths and degree of saturation are mediated not only through effects on serum lipids, but also through effects on haemostatic variables (Dupont et al. 1996). Ulbricht \& Southgate (1991) suggested that the atherogenic or hyperlipidaemic fatty acids are lauric (C12:0), myristic ( $\mathrm{C} 14: 0)$ and palmitic (C16:0) acids, while myristic, palmitic and stearic (C18:0) acids are the thrombogenic fatty acids. The long chain polyunsaturated n-6 (linoleic, C18:2) and the n-3 fatty acids from fish oils are thought to be antiatherogenic and antithrombotic.

The above is an oversimplification. Unfortunately, the relationships of the different fatty acids with haemostatic variables are much more complex. For example, stearic acid, compared with lauric and myristic acids, decreased fasting factor $\mathrm{VII}_{\mathrm{c}}$ in long term dietary interventions (Bladbjerg et al. 1995) but increased factor $\mathrm{VII}_{\mathrm{c}}$ postprandially (Tholstrup et al. 1996). Also, a particular fatty acid may have both procoagulant and anticoagulant activities. Bladbjerg et al. (1995) showed that while stearic acid compared with lauric and myristic acid diets decreased factor VII concentration and activity as well as factors II, X, protein C and prothrombin fragment $1+2$, it increased plasma fibrinogen. From the available literature it is difficult to conclude what the effect of the habitual, long term intake of a particular fatty acid on haemostatic balance will be.

Nevertheless, there are indications that increased intake of the monounsaturated fatty acids lowers von Willebrand factor in non-insulin dependent diabetes mellitus patients (Thomsen $e t$ al. 1995), and that it decreases PAI-1 levels and activity in healthy young men (Lopez-Segura et al. 1996). None of these studies showed any effects of monounsaturated fatty acids on a variety of other haemostatic parameters, including fibrinogen, thrombin-antithrombin complex, prothrombin fragment $1+2$, plasminogen, $\alpha$-2-antiplasmin and tPA.

The effects of different fatty acids on platelet function are intriguing. Mutanen et al. (1995) showed that platelets are less sensitive to aggregating agents in subjects following diets with highly saturated fat than in those on unsaturated fat. Renaud et al. (1986) found that reduction in saturated fat intake from $16.2 \%$ to $9.9 \%$ of dietary energy over a period of one year decreased thrombin stimulated platelet aggregation by $81 \%$ but increased ADP stimulated aggregation by $54 \%$. Freese \& Mutanen (1995) further showed that while fat intake increased factor VII $_{c}$ postprandially, it decreased collagen induced platelet aggregation.

\section{Effects of fish and fish oil intakes}

Although fish intake does not grant a population immunity from CHD (Katan, 1995) protective effects of moderate intakes have been demonstrated (Kromhout et al. 1985). These could be mediated through effects of the long chain, highly unsaturated $n-3$ fatty acids, eicosapentaenoic acid and docosahexaenoic acid in fish on haemostatic variables. 
The relationships of intakes of fish, fish oils, eicosapentaenoic acid and docosahexaenoic acid with haemostatic variables have been studied extensively. Their inhibitory effects on platelet aggregation with resultant prolonged bleeding times through effects on prostanoid metabolism are well known (Dyerberg, 1986). But fish intake also affects coagulating factors and fibrinolytic enzymes. High intakes are associated with lower plasma levels of fibrinogen, factor VIII and von Willebrand factor (Shahar et al. 1993). However, studies which examined the effect of supplementation of diets with fish oil on plasma fibrinogen gave conflicting results. Some studies showed a lowering of fibrinogen (Høstmark et al. 1988), others found no effect (Brown \& Roberts, 1991) while some even demonstrated increases (Schmidt et al. 1992). Haglund et al. (1991) showed that fish oil lowered fibrinogen levels only when it contained $1.5 \mathrm{IU}$ vitamin E/g and not when it contained $0.3 \mathrm{IU} / \mathrm{g}$. Oosthuizen et al. (1994) showed that a vitamin E-rich fish oil lowered plasma fibrinogen in women who had relatively high initial values (from $3.23 \pm 0.96$ to $2.64 \pm 0.55 \mathrm{~g} / \mathrm{l}$ ) but not in men who had low baseline values $(2.03 \pm 0.62 \mathrm{~g} / 1)$. Vitamin $\mathrm{E}$ is known to protect unsaturated fatty acids from oxidation. The possibility that oxidized fatty acids are responsible for the observed increases in fibrinogen should therefore be examined.

Although the safety of fish oil re bleeding episodes and haemostasis in patients with CHD has been demonstrated (Eritsland et al. 1995), the increases in fibrinogen seen in some studies, especially in diabetic patients (Haines et al. 1986) question the safety of these supplements. In several studies it was also reported that increases in PAI-1 occurred, despite decreases in triglyceride levels with fish oil supplementation, in both diabetic (Boberg et al. 1992) and healthy (Oosthuizen et al. 1994) subjects. In addition, Herrmann et al. (1995) reported decreases in tPA with a supplement of $12 \mathrm{~g}$ fish oil in CHD patients. However, fish oil supplementation has other anticoagulant effects. Oosthuizen et al. (1994) reported decreases in factors $\mathrm{V}_{c}, \mathrm{VII}_{\mathrm{c}}$ and $\mathrm{X}_{\mathrm{c}}$ in women with initial high levels, while Osterud et al. (1995) showed a decrease in prothrombin fragment $1+2$ with supplements containing whale oil.

From these studies one might conclude that fish oil inhibits platelet aggregability and lowers some coagulation factors and thrombin generation, but also that it impairs fibrinolytic potential by lowering tPA and raising PAI-1 in some circumstances. Marckmann (1995) is of the opinion that the antifibrinolytic effect of the fish oil fatty acids might counteract their antithrombotic influence on platelet function.

\section{Effects of dietary carbohydrates}

The prudent diet, recommended to lower risk of developing chronic diseases of lifestyle, is high in carbohydrate, including fibre or nonstarch polysaccharides (NSP), low in fat, and relatively higher in plant than animal protein. Studies looking at the independent effect of dietary carbohydrate on haemostasis should therefore control for amounts and types of fat and protein. Because different types of NSP have different physiological effects on gastrointestinal function and lipid metabolism, it can be expected that effects on haemostasis will also differ. Fehily et al. (1982) provided epidemiological evidence that high cereal fibre intakes correlated negatively with plasma fibrinogen. However, in a follow-up study, Fehily et al. (1986) could not demonstrate decreases in fibrinogen when healthy subjects increased their cereal fibre intake. Simpson et al. (1982) also could not demonstrate a change in fibrinogen with increased NSP intake by diabetic patients, but they found that factors $\mathrm{VII}_{\mathrm{c}}$ and $\mathrm{X}_{\mathrm{c}}$ decreased on the higher fibre intake in non-insulin dependent patients, and factor VIII antigen decreased in the insulindependent ones. If fibre intake influences plasma fibrinogen, it is probably owing to the gel- 
forming NSP components. Koepp \& Hegewisch (1981) found that supplementing the daily diet of 10 diabetic children with $0.45 \mathrm{~g}$ guar gum $/ \mathrm{kg}$ for 4 weeks reduced fibrinogen level in 7 of the children from a mean of 3.13 to $2.63 \mathrm{~g} / \mathrm{l}$. Another NSP, konjacglucomannan, significantly lowered plasma fibrinogen in an obese baboon model (Venter et al. 1990) and the obese Zucker rat (Venter et al. 1991).

NSP probably do not affect platelet function. Challen et al. (1983) found no effects on platelet aggregation, platelet fatty acid composition, bleeding times, or dilute blood clot lysis time in healthy volunteers given $36 \mathrm{~g}$ pectin daily for 3 weeks. Sanders \& Roshanai (1992) also found no effect on platelet function of a vegetarian diet which contained no $n-3$ fatty acids.

Much can be learned about the effects of NSP by analysing the diets and disease risk profiles of vegetarians. Haines et al. (1980) showed that factors VII and II were lower in vegetarians, while the only haemostatic difference between Chinese Buddhist vegetarians and omnivores that Pan et al. (1993) could find was increased levels of antithrombin III.

High fibre intakes are associated with increased fibrinolysis. Sundell \& Ranby (1993) demonstrated that oat husk fibre, and Landin et al. (1992) that guar gum, significantly reduced PAI-1 levels. Marckmann et al. (1993) also showed that a low fat, high fibre diet followed for 8 months by healthy volunteers improved fibrinolytic potential by increasing tPA activity. This study did not show changes in fibrinogen or PAl-1. Mehrabian et al. (1990) reported that a 'high complex $\mathrm{CHO}$, low-fat' diet followed for 3 weeks significantly reduced plasminogen, tPA and PAI-1, while fibrinogen tended to decrease $(P=0.07)$. It is however difficult to dissect effects of NSP from those of fat or other factors in these studies.

High NSP diets, therefore, affect coagulation and fibrinolysis. The effects of starch, resistant starch and other carbohydrates such as the oligosaccharides have not been examined. Nor have the possible mechanisms, through which haemostatic effects of NSP may be mediated, received much attention. Venter \& Vorster (1989) hypothesized that the colonic production of short chain fatty acids may contribute. The recent work of Veldman (1996) supports this concept. He reported that pectin intakes of $15 \mathrm{~g} / \mathrm{d}$ increased blood acetate levels, decreased free fatty acid concentrations and improved blood viscosity, fibrin network compaction, fibre diameter, permeability, fibrin content, and lysis of the clot in hypercholesterolaemic subjects.

\section{Effects of micronutrients}

Very few studies have reported effects of vitamins and minerals on coagulation and no clear mechanisms are established. Kruger et al. (1994) observed in healthy elderly women that those who took micronutrient supplements and who had significantly higher levels of serum vitamin A, retinol binding protein, pyridoxal and pyridoxal phosphate also had significantly lower plasma fibrinogen levels. Eliasson et al. (1995) found in the Swedish MONICA study that high plasma retinol levels were associated with lower plasma fibrinogen but also with low IPA and high PAI-1 levels, and therefore with impaired fibrinolytic activity. Hankey et al. (1996) also found positive associations between plasma retinol concentration that had been standardized for total plasma lipids and PAI-1 activity and factor $\mathrm{VII}_{\mathrm{c}}$ in patients with angina. In contrast, Van Giezen et al. (1993), using a rat model, showed that retinoic acid increased fibrinolysis by selectively increasing tPA without affecting PAI-1, uPA, plasminogen or $\alpha$-2-antiplasmin. Their results were confirmed by Van Bennekum et al. (1993) in a vitamin A deficient rat model. In vitro work by Kiserud et al. (1995) showed that vitamin E prevented hyperfibrinogenaemic 
effects of some polyunsaturated fatty acids, probably by preventing oxidation of these fatty acids.

The effects of some micronutrients on platelet function have been studied. Chen et al. (1994) found that rats who were vitamin E deficient showed a prothrombotic state which could be rectified with vitamin E supplementation. Nadler et al. (1992) found that intravenous and oral magnesium supplementation of non-insulin dependent diabetic subjects reduced platelet aggregability.

It is possible that vitamins affecting homocysteine metabolism could also be indirectly involved in haemostasis. Stamler \& Slivka (1996) reviewed the evidence which shows that homocysteine induces activation of factors $\mathrm{V}$ and XII, and that it is associated with inhibition of protein $\mathrm{C}$ because it acts as a competitive inhibitor for thrombin binding to thrombomodulin. Therefore, a detailed investigation of the relationship between homocysteine metabolism and haemostasis may reveal the importance of folate and vitamin $\mathrm{B}_{6}$ for normal haemostasis.

\section{Effects of specific foods}

There is some evidence that specific foods or substances in foods such as the flavonoids or polyphenols may influence haemostasis. Petroni et al. (1995) showed for example that 2-(3,4dihydroxyphenyl-1)-ethanol, a phenolic component with potent antioxidant properties isolated from virgin olive oil, inhibited in vitro platelet aggregation and thromboxane formation. Strongly flavoured foods such as onions (Menon et al. 1968), garlic (Resch \& Ernst, 1995), chillies (Glatzel \& Rüberg-Schweer, 1965), spices (Glatzel \& Rüberg-Schweer, 1967), capsicum (Visudhiphan et al. 1982) or green tea (Ali \& Afzal, 1987) may increase fibrinolytic activity. However, Vorster et al. (1996) found no evidence that fibrinogen, tPA or PAI-1 were influenced by tea drinking. Vorster et al. (1992) also reported that an increased egg intake from 2 to 7 and 14 per week in young healthy men over a period of 5 months did not influence coagulation or fibrinolytic (plasminogen) profiles. The association of high intakes of fruits, vegetables and root vegetables with lower PAI-1 activity reported by Nilsson et al. (1990) could possibly be related to the fibre and/or vitamin $C$ content of these products.

\section{Comments, conclusions and recommendations}

There is no doubt that many dietary substances influence the haemostatic system. There is enough evidence to conclude that some of the protective effects of diet against the development of atherosclerosis, thrombosis and resultant CHD are mediated through effects on haemostasis. Other than the function of vitamin $\mathrm{K}$ in the synthesis of some coagulation factors, it is too early to reach conclusions regarding the essentiality of nutrients for haemostasis. However, with the exception of platelet function which seems to be separately affected, it is clear that both procoagulant and anticoagulant events may be influenced by the same food or nutrient. This is probably the result of the interrelationships between different components of the system, and the compensatory adjustments in one part when another is affected, in an attempt to maintain haemostatic balance. Therefore, to shift this balance, substantial dietary adjustments would probably be needed.

There is not enough evidence to recommend a diet at a population level to protect against hypercoagulability and risk of atherogenesis and thrombogenesis. Much more research is needed. Nevertheless, it seems that the prudent low fat, high fibre diet, rich in antioxidants from 
fruits and vegetables, low in salt, which contains fatty fish and moderate amounts of alcohol, and which would balance energy requirements to maintain ideal body weight, is not only hypolipidaemic but will also protect against hypercoagulability.

The physiological and pathological mechanisms through which diet, as well as other lifestyle factors, influence the different components of the haemostatic system need more clarification before different types of hypercoagulability can be identified, prevented or treated. In this research, measurement of appropriate functional endpoints or markers which reflect the balance in the system (see Table), as well as good dietary control and careful selection of subjects suffering from hypercoagulability, would be necessary. These subjects will probably also have other risk factors for CHD (Mitropoulos, 1994; Genest \& Cohn, 1995) or suffer from diabetes (Simpson et al. 1982) or syndrome X (Daae et al. 1993). The latter is a cluster of metabolic abnormalities associated with resistance to insulin mediated glucose uptake, which includes hypertension and high plasma concentrations of triacylglycerols and insulin.

Much has been learned about the determinants of variances in serum lipoproteins by comparing different ethnic groups. Comparisons of fibrinogen levels between Japanese and Europeans (Iso et al. 1993b), Europeans and Afro-Americans (Folsom et al. 1991) and South Africans of African, Indian, and European origins (Venter et al. 1992) and fibrinolytic activity in Europeans and Africans (Jerling et al. 1994) indicate that this is an area in which more research will contribute to a better understanding of factors which influence haemostasis. Future research on genetic determinants of haemostatic variables and genetic-environmental interactions will also contribute. A better understanding of these may lead to dietary treatments of individual patients suffering from hypercoagulability, and improved recommendations on a population level for the prevention of chronic diseases

\section{References}

Ali, M. \& Afzal, M. (1987). A potent inhibitor of thrombin stimulated platelet thromboxane formation from unprocessed tea. Prostaglandins, Leukotrienes and Medicine 27, 9-13.

Altomare, D. F., Semeraro, N. \& Colucci, M. (1993). Reduction of the plasma levels of tissue plasminogen activator after infusion of a lipid emulsion in humans. Joumal of Parenteral and Enteral Nutrition 17, 274-276.

Assmann, G. \& Schulte, H. (1992). The importance of triglycerides: results from the Prospective Cardiovascular Munster (PROCAM) Study. European Journal of Epidemiology 8 (Suppl. 1), 99-103.

Avellone, G., Di Garbo, V., Cordova, R., Raneli, G., De Simone, R. \& Bompiani, G. D. (1994). Coagulation, fibrinolysis and haemorheology in premenopausal obese women with different body fat distribution. Thrombosis Research 75, 223-231.

Aznar, J. \& Estelles, A. (1994). Role of plasminogen activator inhibitor type 1 in the pathogenesis of coronary artery diseases. Haemostasis 24, 243-251.

Basista, M. H., Joseph, A., Smolen, S., Koterba, A. \& Brecher, A. S. (1994). Acetaldehyde alters coagulation protein function. Digestive Diseases and Sciences 39, 2421-2425.

Bertina, R. M., Van Tilburg, N. H., De Fouw, N. J. \& Haverkate, F. (1992). Thrombin, a link between coagulation activation and fibrinolysis. Annals of the New York Academy of Sciences 667, 239-248.

Bladbjerg, E. M., Marckmann, P., Sandström, B. \& Jespersen, J. (1994). Non-fasting factor VII coagulant activity (F VII:C) increased by high-fat diet. Thrombosis and Haemostasis 71, 755-758.

Bladbjerg, E. M., Tholstrup, T., Marckmann, P., Sandström, B. \& Jespersen, J. (1995). Dietary changes in fasting levels of factor VII coagulant activity (F VII:C) are accompanied by changes in factor VII protein and other vitamin K-dependent proteins. Thrombosis and Haemostasis 73, 239-242.

Boberg, M., Pollare, T., Siegbahn, A. \& Vessby, B. (1992). Supplementation with n-3 fatty acids reduces triglycerides but increases PAI-I in non-insulin-dependent diabetes mellitus. European Journal of Clinical Investigation 22, $645-650$.

Boman, K., Hellsten, G., Bruce, A., Hallmans, G. \& Nilsson, T. K. (1994). Endurance physical activity, diet and fibrinolysis. Atherosclerosis 106, 65-74.

Brown, A. J. \& Roberts, D. C. K. (1991). Fish and fish oil intake: effect on haematological variables related to cardiovascular disease. Thrombosis Research 64, 169-178. 
Calles-Escandon, J., Ballor, D., Harvey-Berino, J., Ades, P. \& Tracy, R. (1996). Amelioration of the inhibition of fibrinolysis in elderly, obese subjects by moderate energy intake restriction. American Joumal of Clinical Nutrition 64, 7-11.

Carr, M. E. \& Alving, B. M. (1995). Effect of fibrin structure on plasmin-mediated dissolution of plasma clots. Blood Coagulation and Fibrinolysis 6, 567-573.

Cepelak, V., Dvorak, J., Vit, L., Cepelakova, H. \& Beranek, V. (1991). Disorders of fibrinolysis and thrombophilic states, risk factors and possibilities of dietary effects. Vnitmi Lekarstvi 37, 13-20.

Challen, A. D., Branch, W. J. \& Cummings, J. H. (1983). The effect of pectin and wheat bran on platelet function and haemostasis in man. Human Nutrition: Clinical Nutrition 37C, 209-217.

Chen, H. W., Hendrich, S. \& Cook, L. R. (1994). Vitamin E deficiency increases serum thromboxane $A_{2}$, platelet arachidonate and lipid peroxidation in male Sprague-Dawley rats. Prostaglandins Leukotrienes and Essential Fatty Acids 51, 11-17.

Collet, J. P., Soria, J., Mirshahi, M., Hirsch, M., Dagonnet, F. B., Caen, J. \& Soria, C. (1993). Dusart syndrome: a new concept of the relationship between fibrin clot architecture and fibrin clot degradability: hypofibrinolysis related to an abnormal clot structure. Blood 82, 2462-2469.

Connelly, J. B., Cooper, J. A. \& Meade, T. W. (1992). Strenuous exercise, plasma fibrinogen, and factor VII activity. British Heart Joumal 67, 351-354; 68, 160.

Daae, L. N. W., Kierulf, P., Landaas, S. \& Urdal, P. (1993). Cardiovascular risk factors: interactive effects of lipids, coagulation and fibrinolysis. Scandinavian Joumal of Clinical and Laboratory Investigation 53 (Suppl. 215), 19-27.

Dittman, W. A. \& Majerus, P. W. (1990). Structure and function of thrombomodulin: a natural anticoagulant. Blood 75, 329-336.

Doll, R., Peto, R., Hall, E., Wheatley, K. \& Gray, R. (1994). Mortality in relation to consumption of alcohol: 13 years' observations on male British doctors. British Medical Journal 309, 911-918.

Dupont, J., Holub, B. J., Knapp, H. R. \& Meydani, M. (1996). Fatty acid-related functions. American Journal of Clinical Nutrition 63, 9915-9935.

Dyerberg, J. (1986). Linolenate-derived polyunsaturated fatty acids and prevention of atherosclerosis. Nutrition Reviews 44, 125-134.

El-Sayed, M. S. \& Davies, B. (1995). A physical conditioning program does not alter fibrinogen concentration in young healthy subjects. Medicine and Science in Sports and Exercise 27, 485-489.

Eliasson, M., Asplund, K., Evrin, P. E., Huhtasaari, F. \& Johansson, I. (1995). Plasma fibrinogen, fibrinolysis and (pro) vitamins; Is there a connection? Fibrinolysis 9, 87-92.

Eritsland, J., Arnesen, H., Seljefiot, I. \& Kierulf, P. (1995). Long-term effects of n-3 polyunsaturated fatty acids on haemostatic variables and bleeding episodes in patients with coronary artery disease. Blood Coagulation and Fibrinolysis 6, 17-22.

Esmon, C. T. (1993). Cell mediated events that control blood coagulation and vascular injury. Annual Review of Cell Biology 9, 1-26.

Fanari, P., Somazzi, R., Nasrawi, F., Ticozzelli, P., Grugni, G., Agosti, R. \& Longhini, E. (1993). Haemorheological changes in obese adolescents after short-term diet. Intemational Journal of Obesity and Related Metabolic Disorders 17, 487-494.

Fatah, K., Hamsten, A., Blomback, B. \& Blomback, M. (1992). Fibrin gel network characteristics and coronary heart disease: relations to plasma fibrinogen concentration, acute phase protein, serum lipoproteins and coronary atherosclerosis. Thrombosis and Haemostasis 68, 130-135.

Fehily A. M., Burr, M. L., Butland, B. K. \& Eastham, R. D. (1986). A randomized controlled trial to investigate the effect of a high fibre diet on blood pressure and plasma fibrinogen. Journal of Epidemiology and Community Health 40, 334-337.

Fehily, A. M., Milbank, J. E., Yamell, J. W. G., Hayes, T. M., Kubiki, A. J. \& Eastham, R. D. (1982). Dietary determinants of lipoproteins, total cholesterol, viscosity, fibrinogen, and blood pressure. American Journal of Clinical Nutrition 36. 890-896.

Ferlito, S. \& Di Mauro, C. (1990). Effects of an oral fat load on some prothrombotic markers in coronary heart patients. Panminerva Medica 32, 101-104.

Folsom, A. R., Qamhieh, H. T., Wing, R. R., Jeffery, R. W., Stinson, V. L., Kuller, L. H. \& Wu, K. K. (1993). Impact of weight loss on plasminogen activator inhibitor (PAI-1), factor VII, and other hemostatic factors in moderately overweight adults. Arteriosclerosis and Thrombosis 13, 162-169.

Folsom, A. R., Wu, K. K., Davis, C. E., Conlan, M. G., Sorlie, P. D. \& Szklo, M. (1991). Population correlates of plasma fibrinogen and factor VII, putative cardiovascular risk factors. Atherosclerosis 91, 191-205.

Freese, R. \& Mutanen, M. (1995). Postprandial changes in platelet function and coagulation factors after high-fat meals with different fatty acid compositions. European Journal of Clinical Nutrition 49, 658-664.

Gelmini, G., Coiro, V., Manotti, C., Delsignore, R. \& Passeri, M. (1989). Effect of diet and weight loss on whole blood filterability and plasma fibrinogen values in hypertensive obese postmenopausal women. Acta Diabetologia Latina 26, 329-335

Genest, J. \& Cohn, J. S. (1995). Clustering of cardiovascular risk factors: targeting high-risk individuals. American Joumal of Cardiology 76, 8A-20A.

Glatzel, H. \& Rüberg-Schweer, M. (1965). [Nutrition and circulation control. 7. Activation of fibrinolysis by spices (chillies).] Kreislaufforschung 53, 374-384. 
Glatzel, H. \& Rüberg-Schweer, M. (1967). [Effects of coagulation and fibrinolysis due to common local spices.] Medizinische Klinik 62, 1086-1088.

Guyton, A. C. (1991). Hemostasis and blood coagulation. Textbook of Medical Physiology, 8th edn, pp. $390-399$. Philadelphia, PA: W. B. Saunders.

Haglund, O., Luostarinen, R., Wallin, R., Wibell, L. \& Saldeen, T. (1991). The effects of fish oil on triglycerides, cholesterol, fibrinogen and malondialdehyde in humans supplemented with vitamin E. Journal of Nutrition 121, $165-169$.

Haines, A. P., Chakrabarti, R., Fisher, D., Meade, T. W., North, W. R. S. \& Stirling, Y. (1980). Haemostatic variables in vegetarians and non-vegetarians. Thrombosis Research 19, 139-148.

Haines, A. P., Sanders, T. A. B., Imeson, J. D., Mahler, R. F., Martin, J., Mistry, M., Vickers, M. \& Wallace, P. G. (1986). Effects of a fish oil supplement on platelet function, haemostatic variables and albuminuria in insulindependent diabetics. Thrombosis Research 43, 643-655.

Hamsten, A. \& Eriksson, P. (1995). Fibrinolysis and atherosclerosis. Baillières Clinical Haematology 8, 345-363.

Hankey, C. R., Rumley, A., Ha, T., Lowe, G. D. O. \& Lean, M. E. J. (1996). Plasma coagulation, fibrinolysis and (pro)vitamins in those with ischaemic heart disease. Fibrinolysis 10, 193.

Hendriks, H. F. J., Veenstra, J., Velthuis-te Wierik, E. J. M., Schaafsma, G. \& Kluft, C. (1994). Effect of moderate dose of alcohol with evening meal on fibrinolytic factors. British Medical Journal 308, 1003-1006.

Herren, T., Stricker, H., Haeberli, A., Do, D. D. \& Straub, P. W. (1994). Fibrin formation and degradation in patients with arteriosclerotic disease. Circulation 90, 2679-2686.

Herrmann, W., Biermann, J. \& Kostner, G. M. (1995). Comparison of effects of n-3 to n-6 fatty acids on serum level of lipoprotein (a) in patients with coronary artery disease. American Joumal of Cardiology 76, 459-462.

Ho, C. H., Chwang, L. C. \& Hwang, B. H. (1995). The influence of high fat diet on the fibrinolytic activity. Thrombosis Research 77, 201-208.

Høstmark, A. T., Bjerkedal, T., Kierulf, P., Flaten, H. \& Ulshagen, K. (1988). Fish oil and plasma fibrinogen. British Medical Journal 297, 180-181.

Howard, B. V., Le, N. A., Bekker, J. D., Flack, J. M., Jacobs, D. R., Lewis, C. E., Macrovina, S. M. \& Perkins, L. L. (1994). Concentrations of $L p(a)$ in black and white young adults: relations to risk factors for cardiovascular disease Annals of Epidemiology 4, 341-350.

Huisveld, I. A., Leenen, R., Van der Kooy, K., Hospers, J. E. H., Seidell, J. C., Deurenberg, P., Koppeschaar, H. P. F., Mosterd, W. L. \& Bouma, B. N. (1990). Body composition and weight reduction in relation to antigen and activity of plasminogen activator inhibitor (PAI-1) in overweight individuals. Fibrinolysis 4 (Suppl. 2), 84-85.

Iso, H., Folsom, A. R., Koike, K. A., Sato, S., Wu, K. K., Shimamoto, T., Iida, M. \& Komachi, Y. (1993a). Antigens of tissue plasminogen activator and plasminogen activator inhibitor 1 : correlates in nonsmoking Japanese and Caucasian men and women. Thrombosis and Haemostasis 70, 475-480.

Iso, H., Folsom, A. R., Sato, S., Wu, K. K., Shimamoto, T., Koike, K. A., Iida, M. \& Komachi, Y. (1993b). Plasma fibrinogen and its correlates in Japanese and US population samples. Arteriosclerosis and Thrombosis 13, 783-790.

Jerling, J. C., Vorster, H. H., Oosthuizen, W., Silvis, N. \& Venter, C. S. (1994). Differences in plasminogen activator inhibitor 1 activity between blacks and whites may be diet related. Haemostasis 24, 364-368.

Juhan-Vague, I., Thompson, S. G. \& Jespersen, J. (1993). Involvement of the hemostatic system in the insulin resistance syndrome. A study of 1500 patients with angina pectoris. Arteriosclerosis and Thrombosis 13, 1865-1873.

Katan, M. B. (1995). Fish and heart disease (editorial). New England Journal of Medicine 332, 1024-1025.

Kiserud, C. E., Kierulf, P. \& Høstmark, A. T. (1995). Effects of various fatty acids alone or combined with vitamin E on cell growth and fibrinogen concentration in the medium of HepG2 cells. Thrombosis Research 80, $75-83$.

Koepp, P. \& Hegewisch, S. (1981). Effects of guar on plasma viscosity and related parameters in diabetic children. European Journal of Pediatrics 137, 31-33.

Kozima, Y., Urano, T., Serizawa, K., Takada, Y. \& Takada, A. (1993). Impaired fibrinolytic activity induced by ingestion of butter: effect of increased plasma lipids on the fibrinolytic activity. Thrombosis Research 70, $191-202$.

Krobot, K., Hense, H. W., Cremer, P., Eberle, E. \& Keil, U. (1992). Determinants of plasma fibrinogen: relation to body weight, waist-to-hip ratio, smoking, alcohol, age, and sex. Results from the second MONICA Augsburg survey 19891990. Arteriosclerosis and Thrombosis 12, 780-788.

Kromhout, D., Bosschieter, E. B. \& De Lezenne Coulander, C. (1985). The inverse relation between fish consumption and 20-year mortality from coronary heart disease. New England Journal of Medicine 312, 1205-1209.

Kruger, A., Vorster, H. H., Venter, C. S. \& Viljoen, M. J. (1994). Increased plasma fibrinogen with age-eugeriatric or pathogeriatric phenomenon? Cardiovascular Journal of Southern Africa 5, 110-116.

Landin, K., Holm, G., Tengborn, L. \& Smith, U. (1992). Guar gum improves insulin sensitivity, blood lipids, blood pressure, and fibrinolysis in healthy men. American Joumal of Clinical Nutrition 56, 1061-1065.

Lee, A. J., Flanagan, P. A., Rumley, A., Fowkes, F. G. R. \& Lowe, G. D. O. (1995). Relationship between alcohol intake and tissue plasminogen activator antigen and other haemostatic factors in the general population. Fibrinolysis 8 , 49-54.

Licata, G., Scaglione, R., Avellone, G., Ganguzza, A., Corrao, B., Amone, S. \& Di Chiara, T. (1995). Hemostatic function in young subjects with central obesity: relationship with left ventricular function. Metabolism 44, 14171421.

Lipinski, B., Federman, S. M. \& Krolewski, A. S. (1995). Macromolecular protein complex of human plasma: interaction with fibrin and fibrinolysis. Thrombosis Research 78, 461-465. 
Lopez-Segura, F., Velasco, F., Lopez-Miranda, J., Castro, P., Lopez-Pedrera, R., Blanco, A. et al. (1996). Monounsaturated fatty acid-enriched diet decreases plasma plasminogen activator inhibitor type 1. Arteriosclerosis. Thrombosis, and Vascular Biology 16, 82-88.

Marckmann, P. (1995). Diet, blood coagulation and fibrinolysis. Danish Medical Bulletin 42, $410-425$.

Marckmann, P., Sandström, B. \& Jespersen, J. (1992). Fasting blood coagulation and fibrinolysis of young adults unchanged by reduction in dietary fat content. Arteriosclerosis and Thrombosis 12, 201-205

Marckmann, P., Sandström, B. \& Jespersen, J. (1993). Favorable long-term effect of a low-fat/high-fiber diet on human blood coagulation and fibrinolysis. Aneriosclerosis and Thrombosis 13, 505-511.

Marques-Vidal, P., Cambou, J. P., Nicaud, V., Luc, G., Evans, A., Arveiler, D., Bingham, A. \& Cambien, F. (1995). Cardiovascular risk factors and alcohol consumption in France and Northern Ireland. Atherosclerosis 115, $225-232$

Meade, T. W., Chakrabarti, R., Haines, A. P., North, W. R. S. \& Stirling, Y. (1979). Characteristics affecting fibrinolytic activity and plasma fibrinogen concentrations. British Medical Joumal i, 153-156.

Mehrabian, M., Peter, J. B., Barnard, R. J. \& Lusis, A. J. (1990). Dietary regulation of fibrinolytic factors Atherosclerosis 84, 25-32.

Mennen, L. I., Schouten, E. G., Grobbee, D. E. \& Kluft, C. (1996). Coagulation factor VII, dietary fat and blood lipids: a review. Thrombosis and Haemostasis 76, 492-499.

Menon, I. S., Kendal, R. Y., Dewar, H. A. \& Newell, D. J. (1968). Effect of onions on blood fibrinolytic activity. British Medical Joumal iii, 351.

Merlini, P. A., Bauer, K. A., Oltrona, L., Ardissino, D. Spinola, A., Cattaneo, M., Broccolino, M., Mannucci, P. M. \& Rosenberg, R. D. (1995). Thrombin generation and activity during thrombolysis and concomitant heparin therapy in patients with acute myocardial infarction. Joumal of the American College of Cardiology 25, 203-209.

Mikhailidis, D. P., Barradas, M. A., Maris, A., Jeremy, J. Y. \& Dandona, P. (1985). Fibrinogen mediated activation of platelet aggregation and thromboxane $A_{2}$ release: pathological implications in vascular disease. Joumal of Clinical Pathology 38, 1166-1171.

Miller, G. J. (1992). Hemostasis and cardiovascular risk. The British and European experience. Archives of Pathology and Laboratory Medicine 116, 1318-1321.

Miller, G. J. (1993). Hyperlipidaemia and hypercoagulability. Progress in Lipid Research 32, 61-69.

Mitropoulos, K. A. (1994). Lipid-thrombosis interface. British Medical Bulletin 50, 813-832.

Morris, J. N. (1994). Exercise in the prevention of coronary heart disease: today's best buy in public health. Medicine and Science in Sports and Exercise 26, 807-814.

Mundal, H. H., Meltzer, H. M. \& Aursnes, I. (1994). Bleeding times related to serum triglyceride levels in healthy young adults. Thrombosis Research 75, 285-291.

Mutanen, M., Krusius, T., Rasanen, L., Freese, R., Vahtera, E. \& Viikari, J. S. A. (1995). Habitual diet, platelet function, fibrinogen and factor VIl coagulant activity in young Finns. Journal of Internal Medicine 237, 577-583.

Nadler, J. L., Malayan, S., Luong. H., Shaw, S., Natarajan, R. D. \& Rude, R. K. (1992). Intracellular free magnesium deficiency plays a key role in increased platelet reactivity in type II diabetes mellitus. Diabetes Care 15, 835-841.

Nair, C. H. \& Dhall, D. P. (1991). Studies on fibrin network structure: the effect of some plasma proteins. Thrombosis Research 61, 315-325.

Nieuwenhuizen, W. (1994). Biochemistry and measurement of fibrinogen. Blood Coagulation and Fibrinolysis 5 (Suppl. 2), 1.

Nilsson, T. K., Sundell, I. B., Hellsten, G. \& Hallmans, G. (1990). Reduced plasminogen activator inhibitor activity in high consumers of fruits, vegetables and root vegetables. Journal of Internal Medicine 227, 267-271

Oosthuizen, W., Vorster, H. H., Jerling, J. C., Barnard, H. C., Smuts, C. M., Silvis, N., Kruger, A. \& Venter, C. S. (1994). Both fish oil and olive oil lowered plasma fibrinogen in women with high baseline fibrinogen levels. Thrombosis and Haemostasis 72, 557-562.

Oosthuizen, W., Vorster, H. H., Jerling, J. C., Lessing, M. C., Veldman, F. J., Kruger, A. \& Vermaak, W. J. H. (1996). Increased plasma fibrinogen levels in 'healthy' obese women. Abstract. XIVth International Fibrinogen Workshop, Canberra, Australia.

Osterud, B., Elvevoll, E., Barstad, H., Brox, J., Halvorsen, H., Lia, K., Olsen, J. O. et al. (1995). Effect of marine oils supplementation on coagulation and cellular activation in whole blood. Lipids 30, 1111-1118.

Packham, M. A. \& Mustard, J. F. (1986). The role of platelets in the development and complications of atherosclerosis Seminars in Hematology 23, 8-26.

Palareti, G., Legnani, C., Poggi, M., Parenti, M., Babini, A. C., Biagi, R., Baraldi, L., Luchi, A., Capelli, M. \& Coccheri, S. (1994). Prolonged very low calorie diet in obese subjects reduces factor VII and PAI but not fibrinogen levels. Fibrinalysis 8, 16-21.

Palareti, G., Maccaferri, M., Poggi, M., Legnani, C. \& Coccheri, S. (1992). Fibrinogen measurement in various clinical conditions: a comparison of five different methods. In Fibrinogen: a 'new' cardiovascular risk factor, pp. 64-67 [E. Ernst, W. Koenig, G. D. O. Lowe and T. W. Meade, editors]. Oxford: Blackwell.

Pan, W. H., Chin, C. J., Sheu, C. T. \& Lee, M. H. (1993). Hemostatic factors and blood lipids in young Buddhist vegetarians and omnivores. American Journal of Clinical Nutrition 58, 354-359.

Peternel, P., Stegnar, M., Mavri, A. \& Salobir-Pajnic, B. (1994). The effect of fasting and/or body weight reduction on tissuetype plasminogen activator (t-PA) and plasminogen activator inhibitor (PAI-1). Fibrinolysis 8 (Suppl. 2), 41-43.

Petroni, A., Blasevich, M., Salami, M., Papini, N., Montedoro, G. F. \& Galli, C. (1995). Inhibition of platelet aggregation and eicosanoid production by phenolic components of olive oil. Thrombosis Research 78, 151-160. 
Pilgeram, L. O. \& Pickart, L. R. (1968). Control of fibrinogen biosynthesis: the role of free fatty acids. Atherosclerosis Research 8, 155-166.

Poggi, M., Palareti, G., Biagi, R., Legnani, C., Parenti, M., Babini, A. C., Baraldi, L. \& Coccheri, S. (1994). Prolonged very low calorie diet in highly obese subjects reduces plasma viscosity and red cell aggregation but not fibrinogen. International Journal of Obesity and Related Metabolic Disorders 18, 490-496.

Rankinen, T., Rauramaa, R., Vaisanen, S., Penttila, I. M. \& Uusitupa, M. (1994). Relation of habitual diet and cardiorespiratory fitness to blood coagulation and fibrinolytic factors. Thrombosis and Haemostasis 71, 180-183.

Rankinen, T., Vaisanen, S., Penttila, I. \& Rauramaa, R. (1995). Acute dynamic exercise increase fibrinolytic activity. Thrombosis and Haemostasis 73, 281-286.

Renaud, S. C., Beswick, A. D., Fehily, A. M., Sharp, D. S. \& Elwood, P. C. (1992). Alcohol and platelet aggregation: the Caerphilly Prospective Heart Disease Study. American Joumal of Clinical Nutrition 55, 1012-1017.

Renaud, S. \& De Logeril, M. (1992). Wine, alcohol, platelets, and the French paradox for coronary heart disease. Lancel 339, 1523-1526.

Renaud, S., Godsey, F., Dumont, E., Thevenon, C., Ortchanian, E. \& Martin, J. L. (1986). Influence of long-term diet modification on platelet function and composition in Moselle farmers. American Journal of Clinical Nutrition $\mathbf{4 3}$, $136-150$

Resch, K. L.\&Ernst, E. (1995). [Garlic (Allium sativum)—a potent medicinal plant.] Fortschritte der Medizin 113,311-315.

Rosenberg, R. D. \& Bauer, K. A. (1992). Does a prethrombotic state exist? If so, what is it? American Journal of Clinical Nutrition 56, 787S-788S.

Rubanyi, G. M. (1993). The role of endothelium in cardiovascular homeostasis and diseases. Journal of Cardiovascular Pharmacology 22 (Suppl. 4), S1-S14.

Sanders, T. A. \& Roshanai, F. (1992). Platelet phospholipid fatty acid composition and function in vegans compared with age- and sex-matched omnivore controls. European Journal of Clinical Nutrition 46, 823-831.

Schmidt, E. B., Lervang, H. H., Varming, K., Madsen, P. \& Dyerberg, J. (1992). Long-term supplementation with n-3 fatty acids. I. Effect on blood lipids, haemostasis and blood pressure. Scandinavian Journal of Clinical and Laboratory Investigation 52, 221-228.

Shahar, E., Folsom, A. R., Wu, K. K., Dennis, B. H., Shimakawa, T., Conlan, M. G., Davis, C. E. \& Williams, O. D. (1993). Associations of fish intake and dietary n-3 polyunsaturated fatty acids with a hypocoagulable profile. The Atherosclerosis Risk in Communities (ARIC) Study. Arteriosclerosis and Thrombosis 13, 1205-1212.

Shattil. S. J. (1992). Why is platelet activation useful for assessing thrombotic risk? What are the advantages and limitations of using flow cytometry to measure platelet activation? American Journal of Clinical Nutrition 56. 789S-790S.

Simpson, H. C. R., Mann, J. I., Chakrabarti, R., Imeson, J. D., Stirling, Y., Tozer, M., Woolf, L. \& Meade, T. W. (1982) Effect of high fibre diet on haemostatic variables in diabetes. British Medical Journal 284, 1608.

Slabber, M., Barnard, H. C., Kuyl, J. M. \& Badenhorst, C. J. (1992). Effect of a short-term very low calorie diet on plasma lipids, fibrinogen, and factor VIl in obese subjects. Clinical Biochemistry 25, 334-335.

Spertini, O., Hauert, J. \& Bachmann, F. (1992). Reaction of acetaldehyde with human platelets. Thrombosis and Haemostasis 67, 126-130.

Stamler, J. S. \& Slivka, A. (1996). Biological chemistry of thiols in the vasculature and in vascular-related disease. Nutrition Reviews 54, 1-30.

Struck, M., Watkins, T., Tomeo, A., Halley, J. \& Bierenbaum, M. (1994). Effect of red and white wine on serum lipids, platelet aggregation, oxidation products and antioxidants: a preliminary report. Nutrition Research 14, $1811-1819$.

Stubbs, C. D. \& Rubin, R. (1992). Effect of ethanol on platelet phospholipase A 2 . Lipids 27, 255-260.

Sundell, I. B.. Dahlen, G. H. \& Ranby, M. (1991). Diet-induced changes in glucose and triglycerides are associated with changes in plasminogen activator inhibitor levels. Haemostasis 21, 175-180.

Sundell, I. B., \& Ranby, M. (1993). Oat husk fiber decreases plasminogen activator inhibitor type 1 activity. Haemostasis 23, 45-50.

Suzuki, T., Yamanchi, K., Yamada, Y., Furumichi, T., Furui, H., Tsuzuki, J., Hayashi, H., Sotobata, 1. \& Saito, H. (1992). Blood coagulability and fibrinolytic activity before and after physical training during the recovery phase of acute myocardial infarction. Clinical Cardiology 15, 358-364.

Svendsen, O. L., Hassager, C., Christiansen, C., Nielsen, J. D. \& Winther, K. (1996). Plasminogen activator inhibitor-1, tissue-type plasminogen activator, and fibrinogen: effect of dieting with or without exercise in overweight postmenopausal women. Areriosclerosis, Thrombosis, and Vascular Biology 16, 381-385.

Takada, A., Takada, Y. \& Urano, T. (1994). The physiological aspects of fibrinolysis. Thrombosis Research 76, 1-31.

Tanaka, K. \& Sueishi, K. (1993). Biology of disease. The coagulation and fibrinolysis systems and atherosclerosis. Laboratory Investigation 69, 5-17.

Tholstrup, T., Andreasen, K. \& Sanstrom, B. (1996). Acute effect of high-fat meals rich in either stearic or myristic acid on hemostatic factors in healthy young men. American Joumal of Clinical Nutrition 64, 168-176.

Thomsen, C., Rasmussen, O. W., Ingerslev, J. \& Hermansen, K. (1995). Plasma levels of von Willebrand factor in noninsulin-dependent diabetes mellitus are infuenced by dietary monounsaturated fatty acids. Thrombosis Research 77 , 347-356.

Tripodi, A., Mannucci, P. M., Chantarangkul, V., Bottasso, B., Arbini, A. A., DellaBella, S. \& Scorza, R. (1993). Markers of procoagulant imbalance in patients with localized melanomas and autoimmune disorders. British Journal of Haematology 84, 670-674. 
Ulbricht, T. L. V. \& Southgate, D. A. T. (1991). Coronary heart disease: seven dietary factors. Lancet 338, $985-992$.

Uno, M., Tsuji, H., Watanabe, M., Takada, O., Kobayashi, K., Takabuchi, H. et al. (1989). Application of thrombinantithrombin III complex for detecting a latent hypercoagulable state in patients with coronary artery disease. Japanese Circulation Journal 53, 1185-1191.

Vague, P., Juhan-Vague, I., Aillaud, M. F., Badier, C., Viard, R., Alessi, M. C. \& Collen, D. (1986). Correlation between blood fibrinolytic activity, plasminogen activator inhibitor level, plasma insulin level, and relative body weight in normal and obese subjects. Metabolism 35, 250-253.

Vaisanen, S., Rankinen, T., Penttila, I. \& Rauramaa, R. (1995). Factor VII coagulant activity in relation to serum lipoproteins and dietary fat in middle-aged men. Thrombosis and Haemostasis 73, 435-438.

Van Bennekum, A. M., Emeis, J. J., Kooistra, T. \& Hendriks, H. F. J. (1993). Modulation of tissue-type plasminogen activator by retinoids in rat plasma and tissues. American Journal of Physiology 264, R931-R937.

Van der Bom, J. G., Bots, M. L., Haverkate, F., Grobbee, D. E. \& Kluft, C. (1996). Fibrinolytic capacity and risk of myocardial infarction. Fibrinolysis 10 (Suppl. 2), 9-12.

Van Giezen, J. J. J., Boon, G. d. i. A., Jansen, J. W. C. M. \& Bouma, B. N. (1993). Retinoic acid enhances fibrinolytic activity in-vivo by enhancing tissue type plasminogen activator (t-PA) activity and inhibits venous thrombosis. Thrombosis and Haemostasis 69, 381-386.

Vanninen, E., Laitinen, J. \& Uusitupa, M. (1994). Physical activity and fibrinogen concentration in newly diagnosed NIDDM. Diabetes Care 17, 1031-1038.

Veenstra, J., Kluft, C., Van der Pol, H., Dooijewaard, G. \& Schaafsma, G. (1993). Acute effects of moderate alcohol consumption on fibrinolytic factors in healthy middle-aged men. Fibrinolysis 7, 177-183.

Veldman, F. J. (1996). Possible mechanisms through which pectin influences fibrinogen concentration and fibrin network structure. PH. D.thesis, PU for CHE, Potchefstroom, $238 \mathrm{pp}$.

Velthuis-te Wierik, E. J. M., Kluft, C., Van den Berg, H. \& Weststrate, J. A. (1996). Consumption of reduced-fat products, haemostatic parameters and oral glucose tolerance test. Fibrinolysis 10, 159-166.

Venter, C. S. \& Vorster, H. H. (1989). Possible metabolic consequences of fermentation in the colon for humans. Medical Hypotheses 29, 161-166.

Venter, C. S., Vorster, H. H., Silvis, N., Kruger, A., Mia, F. \& Seftel, H. C. (1992). Determinants of plasma fibrinogen level in South African communities. In Fibrinogen: a 'new' cardiovascular risk factor, pp. 166-171 [E. Ernst, W. Koenig, G. D. O. Lowe and T. W. Meade, editors]. Oxford: Blackwell.

Venter, C. S., Vorster, H. H. \& Van der Nest, D. G. (1990). Comparison between physiological effects of konjacglucomannan and propionate in baboons fed 'western' diets. Joumal of Nutrition 120, 1046-1053.

Venter, C. S., Vorster, H. H., Van der Nest, D. G. \& Wight, A. W. (1991). Effects of Konjac-glucomannan and proprionate on plasma fibrinogen and serum and liver lipids in Zucker rats. South African Journal of Clinical Nutrition 4(1), 6-11.

Verstraete, M. (1991). Biology and chemistry of thrombosis. In Thrombolysis: basic contributions and clinical progress, pp. 3-16 [E. Haber and E. Braunwald, editors]. St Louis, MO: Mosby Year Book Inc.

Visudhiphan, S., Poolsuppasit, S., Piboonnukarintr, O., \& Tumliang, S. (1982). The relationship between high fibrinolytic activity and daily capsicum ingestion in Thais. American Joumal of Clinical Nutrition 35, 1452-1458.

Vorster, H. H., Badenhorst, C., Barnard, H. C., Walker, A. R. P., Kruger-Locke, M. M. \& Van Jaarsveld, P. (1989). Effects of weight reduction on plasma fibrinogen levels and other metabolic variables in obese women. South African Joumal of Clinical Nutrition 2(2), 8-13.

Vorster, H. H., Benadé, A. J. S., Barnard, H. C., Locke, M. M., Silvis, N., Venter, C. S., Smuts, C. M., Engelbrecht, G. P. \& Marais, M. P. (1992). Egg intake does not change plasma lipoprotein and coagulation profiles. American Joumal of Clinical Nutrition 55, $400-410$.

Vorster, H. H., Cummings, J. H. \& Veldman, F. J. (1997). Diet and haemostasis: time for nutrition science to get more involved. British Joumal of Nutrition 77, 671-684.

Vorster, H., Jerling, J., Oosthuizen, W., Cummings, J., Bingham, S., Magee, L., Mulligan, A. \& Runswick, S. (1996). Tea drinking and haemostasis: a randomized, placebo-controlled crossover study in free-living subjects. Haemostasis 26, 58-64.

Vorster, H. H., Silvis, N., Venter, C. S., Van Ryssen, J. J., Huisman, H., Van Eeden, T. S. \& Walker, A. R. P. (1987). Serum cholesterol, lipoproteins and plasma coagulation factors in South African blacks on a high egg but low-fat intake. American Journal of Clinical Nutrition 46, 52-57.

Vorster, H. H. \& Venter, C. S. (1994). Fibrinogen-a cardiovascular risk factor. Cardiovascular Joumal of Southerm Africa 5, 117-123.

Walker, F. J. \& Fay, P. J. (1992). Regulation of blood coagulation by the protein C system. FASEB Journal 6, 25612567.

Wang, J. S., Jen, C. J. \& Chen, H. I. (1995). Effects of exercise training and deconditioning on platelet function in men. Aneriosclerosis, Thrombosis, and Vascular Biology 15, 1668-1674.

Weidtmann, A., Scheithe, R., Hrboticky, N., Pietsch, A., Lorenz, R. \& Siess, W. (1995). Mildly oxidized LDL induces platelet aggregation through activation of phospholipase $\mathrm{A}_{2}$. Arteriosclerosis, Thrombosis and Vascular Biology 15, $1131-1138$. 